\title{
Human oesophageal bicarbonate secretion: a phenomenon waiting for a role
}

The oesophagus is not simply a conduit between the pharynx and stomach for food and fluid boluses, but is a secretory organ in some species! There is now evidence that neutralisation of refluxed acid within the oesophagus may be achieved by local alkali secretion as well as from swallowed salivary bicarbonate.

The opossum oesophagus was shown to secrete electrolytes in 1980, but in 1989 Hamilton and Orlando demonstrated alkali secretion in an isolated segment of opossum oesophagus, using an in vivo $\mathrm{pH}$ stat technique. ${ }^{1}$ The magnitude of this secretion was sufficient to neutralise acid and increased in response to acid perfusion and local release of acetylcholine acting on muscarinic type 1 receptors. ${ }^{2}$ Oesophageal secretion of bicarbonate probably arises from submucosal glands as rabbit oesophagus devoid of such glands does not secrete alkali. ${ }^{1}$ The relevance of these observations to human physiology arises from the demonstration of an extensive plexus of submucosal glands, similar to those in the opossum, and the presence of the cellular enzyme carbonic anhydrase necessary to generate bicarbonate ions in the human oesophagus. ${ }^{34}$

The existence of human oesophageal bicarbonate secretion was demonstrated by two groups of investigators working simultaneously. Meyers and Orlando isolated an oesophageal segment between two occluding balloons and reported basal alkali secretion of $78 \mu \mathrm{Eq} / 30$ minutes in healthy volunteers. ${ }^{5}$ As the occluding balloons were poorly tolerated, these studies were of short duration and in the absence of a volume marker may have underestimated the magnitude of secretion. Only one other group has been successful in using a balloon occluded human oesophagus. Namiot et al used the technique to measure oesophageal mucus secretion, reporting its responsiveness to topical acid. ${ }^{6}$ Such experiments on an occluded segment of oesophagus should provide "cleaner" results, but this theoretical advantage has been outweighed by the poor tolerance of the balloons.

In view of this intolerance to balloon occlusion, Brown et al investigated oesophageal bicarbonate secretion using a perfusion technique. An open segment of oesophagus was perfused and corrections made for the small amounts of contamination from inadvertently swallowed saliva and refluxed gastric juice. An initial study reported a high basal bicarbonate secretion of $489 \mu \mathrm{mol} / 10 \mathrm{~cm} / \mathrm{h},{ }^{7}$ but in subsequent reports basal secretion was lower at around $300 \mu \mathrm{mol} / 10 \mathrm{~cm} / \mathrm{h}^{8}{ }^{8}$ These studies involved calculated corrections for contamination from swallowed saliva and refluxed gastric contents which reduces the "signal to noise" ratio in such data. The perfusion technique also permitted longer periods of experimental observation, allowing the investigation of some modulating influences, such as neural activity and topical acid.

In this issue Mertz-Nielsen and colleagues (see page 582) provide further evidence for the existence of human oesophageal bicarbonate secretion, using a very similar method to that of Brown et al. With the failure of balloon occlusion, the authors perfused an open segment of human oesophagus with isotonic saline containing a volume marker and measured bicarbonate outputs from the aspirates. With corrections made for contamination by saliva and gastric fluid, the basal rates for oesophageal bicarbonate secretion were 89 and $121 \mu \mathrm{mol} / 10 \mathrm{~cm} / \mathrm{h}$ in two groups of healthy volunteers. The rate of secretion was lower than reported by Brown et al (300-489 $\mu \mathrm{mol} /$ $10 \mathrm{~cm} / \mathrm{h}){ }^{8}{ }^{9}$ This variability in basal secretion is partly because of the small number of subjects in each study and partly because of differences in methods - the study MertzNielsen et al showing better recovery of the infused marker than with previous techniques.

Mertz-Nielsen et al assessed the influence of ranitidine and omeprazole on oesophageal bicarbonate secretion, without providing any plausible cellular target for these two drugs. They failed to measure basal secretion before treatment and cannot, therefore, comment on the influence of each drug on normal bicarbonate output. There seemed to be no difference between the response to ranitidine and omeprazole and, given their pharmacological modes of action on parietal secretion, it seems unlikely that either drug influences local bicarbonate secretion.

The physiological relevance of human oesophageal bicarbonate secretion has not been studied systematically and therefore remains speculative at present. Oesophageal mucosal damage results from refluxed gastric fluid containing acid, pepsin and bile salts, with competence of the lower oesophageal sphincter, secondary oesophageal peristalsis and swallowed saliva remaining the major defence mechanisms. ${ }^{10}$ It is possible that oesophageal production of bicarbonate assumes greater importance in the absence of swallowed saliva, such as during sleep. The limited data currently available show that human oesophageal bicarbonate secretion responds to certain neurogenic factors, although physiological vagal stimulation failed to increase basal secretion. ${ }^{10}$ Some human data is at variance with observations in the opossum, which failed to show any regulatory role for the autonomic nervous system in oesophageal bicarbonate secretion. ${ }^{2}$ Human oesophageal bicarbonate secretion also responds to local acidification (threefold increase with $10 \mathrm{mM} \mathrm{HCl}$ and 32 -fold increase with $100 \mathrm{mM} \mathrm{HCl}^{8}$ and this may have important implications for oesophageal neutralisation of refluxed acid. However, it should be noted that the oesophageal acid load used in these experiments is much greater than would be expected in patients with pathological gastro-oesophageal reflux.

One reasonable conclusion that can be drawn from all these studies is that the human oesophagus secretes bicarbonate. The most likely source is submucosal glands and the secretion seems to be responsive to certain neurogenic stimuli and local acidification. Mertz-Nielsen 
and colleagues have not only confirmed the existence of bicarbonate secretion by the normal human oesophagus, but have refined the perfusion technique. The scene is therefore set for future studies that will hopefully explore the relevance of this secretion to human physiology and the pathogenesis of gastro-oesophageal reflux disease.

Consultant Physician

COLIN M BROWN

Department of Medicine,

Royal Lancaster Infirmary,

Ashton Road, Lancaster LA1 4RP

WYNNE D W REES

Consultant Physician and Honorary Reader in Medicine,

Department of Gastroenterology,

Hope Hospital, Eccles Old Road,

University of Manchester

School of Medicine

Salford M6 $8 \mathrm{HD}$
1 Hamilton $\mathrm{BH}$, Orlando RC. In vivo alkaline secretion by mammalian oesophagus. Gastroenterology 1989; 97: 640-648.

2 Hamilton BH, Tobey NA, Starnes MC, Schreiner VJ, Orlando RC. Effect of adrenergic and cholinergic agents on oesophageal bicarbonate secretion in opossums. Am $\mathcal{F}$ Physiol 1994; 267: G67-70.

3 Hopwood D, Coghill G, Sanders DSA. Human oesophageal submucosal glands. Their detection, mucin, enzyme and secretory protein content. Histochemistry 1986; 86: 107-12.

4 Christie KN, Thomson C, Morley S, Anderson J, Hopwood D. Carbonic anhydrase is present in human oesophageal epithelium and submucosal glands. Histochem 7 1995; 27: 587-90.

5 Meyers RL, Orlando RC. In vivo bicarbonate secretion by human esophagus. Gastroenterology 1992; 103: 1174-8.

6 Namiot Z, Sarosiek J, Rourk RM, Hetzel DP, McCallum RW. Human esophagealsecretion: mucosal response to luminal acid and pepsin. Gastroenterology 1994; 106: 973-81.

7 Brown CM, Snowdon CF, Slee B, Sandle LN, Rees WDW. Measurement of bicarbonate output from the intact human oesophagus. Gut 1993; 34: $872-80$

8 Brown CM, Snowdon CF, Slee B, Sandle LN, Rees WDW. Effect of topical oesophageal acidification on human salivary and oesophageal bicarbonate secretion. Gut 1995, 36: 649-53

9 Brown CM, Snowdon CF, Slee B, Sandle LN, Rees WDW. Neural influences on human esophageal and salivary alkali secretion. Dig Dis Sci 1995; 40: 1642-50.

10 Brown CM, Rees WDW. Factors protecting the oesophagus against acidmediated injury. Aliment Pharmacol Ther 1995; 9: 251-62. 